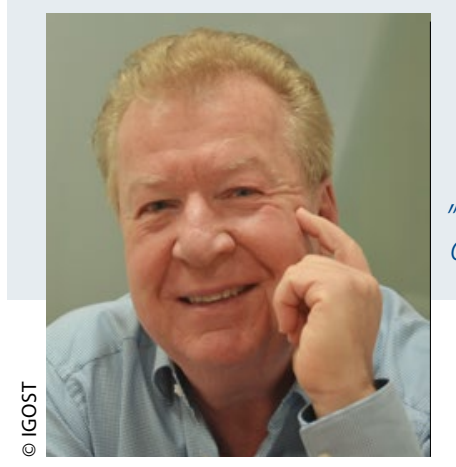

"IEin Niedergelassener ist per se Chefarzt, jeder Patient wird in der Praxis vom Chefarzt behandelt."

\author{
Dr. Martin Strohmeier
}

Ehrensenator der IGOST

\title{
Schmerzspitzen
}

\section{Selbstständigenlust oder Klinikfrust}

D as Zentralinstitut für die kassenärztliche Versorgung (ZI) lässt verlautbaren: „Wer die ambulante Versorgung stärken will, muss niedergelassenen Ärzten einen finanziellen Unternehmerbonus ermöglichen." Ja, die Sicherheitsfanatiker bleiben und blieben schon immer lieber an der Klinik, hat man dort doch immer einen Chef, der letztlich die Verantwortung übernimmt, ein geregeltes Einkommen, ein sicheres Angestelltenverhältnis, eine kommunale Zusatzrentenversicherung, ein 13. Monatsgehalt (als ob irgendjemand auf der Welt jemals 13 Monate im Jahr gearbeitet hätte), Urlaubsgeld - und eine zunehmend großzügige Überstundenregelung.

Ambitionierte Medizin konnte man früher vermutlich mal machen, aber der Op.-Katalog sollte auch voll werden und so gesellte sich zur ambitionierten Medizin mit den Jahren auch eine Aufweichung der Operastionsindikationen. Nicht von ungefähr werden in Deutschland mehr Bandscheiben operiert als sonst wo auf dieser Welt und bei aller Operationswütigkeit hat die Volksgesundheit in Deutschland nicht zugenommen. Dass mit der Häufigkeit erbrachter Leistungen die Ergebnisqualität steigt, ist evidenzbasiert, aber „dass ein nicht an der Bandscheibe Operierter auch nicht am Postdiskotomiesyndrom erkranken kann, bedarf keiner Evidenz, es ist schlicht Tatsache" (Zitat Prof. Krämer, Bochum). Die klinische Medizin ist sicher ambitioniert, aber sie wird immer teurer, anonymer und wenn der Patient mit dem Ergebnis nicht zufrieden ist, hat er keinen Ansprechpartner, zieht man sich darauf zurück, dass die Operation technisch gut durchgeführt wurde.

Dass das Deutsche Ärzteblatt (Jg 114, Heft 6) niedergelassene Ärzte mit Oberärzten vergleicht (und feststellt, dass Niedergelassene weniger verdienen, aber mehr arbeiten als Oberärzte), hinkt bereits im Ansatz, denn ein Niedergelassener ist per se Chefarzt, jeder Patient wird in der Praxis vom Chefarzt behandelt. Aber er ist nicht nur Chefarzt, sondern auch Personalchef und Unternehmer eines mittelständischen Unternehmens. Und während sich der
Kliniker um Personal und Gehälter keine Gedanken machen muss, trägt der Niedergelassene die finanziellen Folgen einer gewerkschaftlich erstrittenen Gehaltserhöhung seiner Angestellten zunächst einmal selber. Auf der anderen Seite werden mit den Abgaben und Steuern auch der Niedergelassenen über die öffentliche Hand wirtschaftlich uneffektive Klinikambulanzen subventioniert, die dem Niedergelassenen noch direkt Konkurrenz machen. Eigentlich gäbe es dafür den Begriff des Subventionsbetruges, dee gilt aber offenbar nicht, wenn die Kommunen und der Staat ihn begehen.

Praxen arbeiten effizienter, wirtschaftlicher, ehrlicher als Kliniken. Überleben kann nur der, der Leistung, Erträge, Personal und Wirtschaftlichkeit im Blick hat. Praxischefs haben keine Kommunen oder Länder im Rücken, die Defizite akzeptieren, tolerieren, subventionieren, um aus politischem Kalkül „ihr“ Krankenhaus präsentieren zu können.

Dass nur noch wenige Ärzte diesen unternehmerischen, verantwortlichen und restriktionsbeladenen Weg wählen und sich lieber im sicheren Schoß einer Klinik wiegen lassen, liegt auf der Hand. Es ist höchste Zeit, dass KV, ZI und auch die Krankenkassen erkennen, dass chirurgische Leistungen besser, wirtschaftlicher und verantwortlicher in ambulanten Praxen erbracht werden können. Klappen kann dies aber nur, wenn dem Arzt ein unternehmerischer finanzieller Bonus möglich ist.

Durch finanzielle Anreize werden in Zukunft vielleicht eher monetär Ambitionierte den Weg in die Niederlassung suchen, die medizinisch Ambitionierten, flexibel, eigenverantwortlich und mit Unternehmergeist findet man dort schon lange.

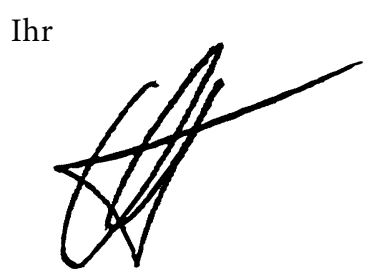

